\title{
Cinética do P nos tecidos de suínos em crescimento alimentados com dietas formuladas de acordo com o conceito de proteína ideal e suplementadas com enzima fitase
}

\author{
[Phosphorus kinetic in growing pigs tissue fed diets formulated according to the ideal \\ protein concept and supplemented with phytase enzyme] \\ J.A. Moreira ${ }^{1}$, D.M.S.S. Vitti ${ }^{2}$, R.M. Patino ${ }^{3}$, B. Berenchtein ${ }^{2}$, T.S. Silva ${ }^{2}$ \\ ${ }^{1}$ Universidade Federal do Rio Grande do Norte (UFRN) - Natal, RN \\ ${ }^{2}$ Centro de Energia Nuclear na Agricultura (CENA) - Piracicaba, SP \\ ${ }^{3}$ Universidade de Sucre - Bogotá - Colômbia
}

\begin{abstract}
RESUMO
O presente estudo foi desenvolvido para avaliar os efeitos da enzima fitase sobre a cinética do $\mathrm{P}$ nos tecidos de suínos, alimentados com dietas formuladas de acordo com o conceito de proteína ideal e suplementadas com enzima fitase. Foram utilizados 20 suínos machos castrados, distribuídos em um delineamento em blocos ao acaso, com cinco tratamentos e quatro repetições. Os animais foram alojados em gaiolas metabólicas durante 17 dias, sendo 10 dias para adaptação e sete dias para coletas de fezes e urina. Amostras de sangue foram coletadas por cinco dias. No primeiro dia da fase experimental, cada animal recebeu, por via endovenosa, uma solução radioativa com $7,4 \mathrm{MBq}$ de ${ }^{32} \mathrm{P}$. No final do período experimental, os animais foram sacrificados, e amostras de tecidos do músculo (lombo), coração, fígado, rins e ossos foram coletadas. A enzima fitase interferiu na cinética do ${ }^{32} \mathrm{P}$, levando a uma menor incorporação nos tecidos dos ossos.
\end{abstract}

Palavras-chave: nutrição animal, aminoácidos digestíveis, fitato, poluição ambiental

\begin{abstract}
This study was developed to evaluate the kinetic of the $P$ in the pigs' tissues, feed diets formulated according the ideal protein concept and supplemented with phytase enzyme. Twenty male pigs were used, distributed in a randomized blocks experimental design, with five treatments and four replicates. The animals were housed in metabolic cages for 17 days, with 10 days for adaptation and 7 days for collection of feces and urine. Blood samples were collected in 5 days. On first day of the experimental phase, each animal was intravenously injected with $7.4 \mathrm{MBq} 32 \mathrm{P}$. At the end of the experiment the animals were slaughtered and samples of muscle (loin), heart, liver, kidney and bones were collected. The enzyme fitase interfered in the kinetics of $32 P$, leading to a smaller incorporation of bone tissues.
\end{abstract}

Keywords: animal nutrition, digestible amino acid, environmental pollution, phytate

\section{INTRODUÇÃO}

Os suínos são animais que possuem crescimento rápido, o que leva à ingestão de grandes quantidades de alimentos, elevando, consequentemente, a quantidade de dejetos produzidos; assim, caracteriza-se como indispensável o uso de dietas ajustadas de acordo com as necessidades dos animais (Moreira et al., 2011).

O P desempenha papel fundamental no metabolismo animal, por estar envolvido em inúmeras reações bioquímicas, permitindo o acontecimento de todos os eventos necessários ao crescimento e desenvolvimento dos animais (Agudelo et al., 2010).

Recebido em 15 de março de 2013

Aceito em 18 de dezembro de 2013

E-mail: japmoreira@bol.com.br 
Rações desbalanceadas em P afetam a absorção de cálcio e reduzem a taxa de crescimento dos tecidos, diminuindo o crescimento dos animais e o desenvolvimento dos ossos. Nos últimos anos, diversos pesquisadores no Brasil e em várias regiões do mundo têm pesquisado os mais diferentes aspectos que envolvem o uso do $\mathrm{P}$ no metabolismo dos animais (Teixeira et al., 2004a; Moreira et al,. 2004; Arouca et al., 2009). O que se pretende é produzir dietas por um custo mais reduzido, as quais permitam maximizar o desenvolvimento dos animais e minimizar as excreções de $\mathrm{P}$.

A maior rota de excreção do $\mathrm{P}$ é pelas fezes, seguida pela fração endógena, que apresenta valores superiores à excreção na urina (Lopes et al., 2009a).

Os dejetos de suínos podem ser utilizados como substrato para produção de biogás e como fertilizantes, entretanto muitos produtores de suínos ainda não se conscientizaram da importância do manejo adequado dos dejetos para reduzir os impactos ambientais. Em algumas regiões do Brasil, os impactos provocados pela poluição devido ao manejo dos dejetos são insustentáveis (Meinerz et al., 2011), sendo necessária a criação de leis mais restritivas, pois, no futuro, os danos serão irreparáveis.

Os dejetos de suínos são normalmente ricos em nutrientes, principalmente $\mathrm{P}$ e $\mathrm{N}$; assim, quando não são manejados corretamente, podem contaminar as águas, provocando eutrofização e, consequentemente, levando à mortalidade de peixes e organismos aquáticos (Bennett et al., 2001).

Na nutrição de suínos, a combinação de alimentos ricos em $\mathrm{P}$ total, como farelo de arroz integral e desengordurado, permite a retirada total das fontes de fósforo inorgânico, com a adição de cerca de $750 \mathrm{UF} / \mathrm{kg}$ de dieta, para suínos em crescimento, o que pode levar à redução do custo das dietas e do impacto ao ambiente pela menor excreção de $\mathrm{P}$ nos dejetos (Moreira, 2002).

A enzima fitase tem demonstrado ser eficiente em disponibilizar o $\mathrm{P}$ complexado nas moléculas de fitato, conforme diversos experimentos desenvolvidos (Ludke et al., 2002; Moreira et al., 2003), entretanto poucos estudos reportam os efeitos dessa enzima após a absorção.

Muitos trabalhos já foram desenvolvidos com o propósito de estudar a digestibilidade do fitato e a absorção do P (Machinsky et al., 2010), mas poucos abordaram os efeitos da fitase sobre a cinética nos tecidos.

O uso de material radioativo proporciona condições para o acompanhamento passo a passo do elemento estável em associação ao radioativo, permitindo o acompanhamento da trajetória do mineral pelo metabolismo animal (Vitti e Kebreab, 2010).

$\mathrm{O}{ }^{32} \mathrm{P}$ é um isótopo do ${ }^{31} \mathrm{P}$, mas é radioativo, sendo produzido artificialmente. No metabolismo animal, os isótopos têm comportamento similar, o que permite o estudo do isótopo estável pela monitoração do seu isótopo radioativo (Vitti e Kebreab, 2010).

O estudo da cinética nos tecidos é desenvolvido baseado na atividade específica (AE), que representa a relação entre os átomos dos isótopos radioativos e estáveis, observados no plasma e nos tecidos (Lopes, 1998).

A atividade específica padronizada (AEP) representa a padronização da concentração do isótopo radioativo em relação ao peso do animal, e a atividade específica relativa (AER) quantifica a velocidade de utilização do mineral pelos tecidos (Lopes, 1998).

Após a aplicação do radiotraçador, a $\mathrm{AE}$ no plasma e nos fluidos extracelulares é mais elevada do que nas células, mas o intercâmbio do elemento faz com que a $\mathrm{AE}$ dos tecidos aumente até se igualar com o plasma, quando o valor da atividade específica será igual a um (Bueno, 1997).

O objetivo do presente estudo foi avaliar as influências do uso de diferentes níveis de enzima fitase nas dietas para suínos em relação à cinética do $\mathrm{P}$ nos tecidos.

\section{MATERIAL E MÉTODOS}

Foram utilizados 20 leitões mestiços, machos castrados, com peso médio de $26,8 \mathrm{~kg}$, alojados em gaiolas metabólicas. Os tratamentos consistiram dos seguintes níveis de enzima fitase 
(Quantun Phytase): 0, 250, 500, 750 e 1000FTU/kg de ração.

As dietas experimentais foram formuladas à base de milho e farelo de soja, contendo $14 \%$ de PB e $3250 \mathrm{kcal}$ de EM, e suplementadas com aminoácidos (L-lisina, DL-metionina, L-treonina e L-triptofano), minerais e vitaminas, para atender as necessidades nutricionais de suínos na fase de crescimento, seguindo as recomendações sugeridas por Rostagno et al. (2011), exceto em fósforo.

As rações foram compostas por $84,03 \%$ de milho, $13,50 \%$ de farelo de soja, $0,372 \%$ de fosfato bicálcico, $0,64 \%$ de calcário, 0,025 de premix vitamínico- $41,0,025 \%$ de premix vitamínico-25, 0,10\% de premix mineral, $0,51 \%$ de L-lisina $(98,5 \%), 0,11 \%$ de DL-metionina (99,5\%), 0,18\% de L-treonina $(98,5 \%)$ e $0,05 \%$ de L-triptofano $(98,5 \%)$ e diferentes níveis de fitase $(0,0,01 ; 0,02 ; 0,03 ;$ e $0,04 \%)$.

As dietas foram calculadas de acordo com o consumo metabólico $\left(\mathrm{W}^{0,75}\right)$ e umedecidas na proporção de 1:1 água/ração, sendo fornecidas aos animais em duas refeições diárias, às $7 \mathrm{~h} 30 \mathrm{e}$ às $15 \mathrm{~h} 30$.

$\mathrm{Na}$ fase de adaptação, os animais foram estimulados a consumirem o máximo de ração. Entretanto, na fase de coleta, visando evitar sobras, as quantidades de ração em cada tratamento foram baseadas no menor consumo entre os animais do bloco, obtido no período préexperimental. A água foi oferecida à vontade.

O experimento foi desenvolvido no período de 17 dias, sendo 10 dias para adaptação e sete dias para coletas de sangue, fezes e urina.
No início da fase experimental, cada animal recebeu, por via endovenosa, $0,5 \mathrm{~mL}$ de uma solução radioativa com $7,4 \mathrm{MBq}$ de ${ }^{32} \mathrm{P}$.

A solução radioativa, preparada de acordo com Vitti et al. (2006), constituiu-se de fosfato de sódio $\left(\mathrm{Na}_{2} \mathrm{H}^{32} \mathrm{PO}_{4}\right)$, livre de carregador, e foi adquirida no Instituto de Pesquisas Energéticas Nucleares (IPEN). Após a aplicação do material radioativo, foram coletados diariamente, durante sete dias, $10 \mathrm{~mL}$ de sangue, com o uso de tubos a vácuo heparinizados, em intervalos de 24 horas.

No final do período experimental, os animais foram abatidos, e amostras dos ossos $\left(10^{\mathrm{a}}\right.$ a $14^{\mathrm{a}}$ costelas), fígado, coração, rins e músculo (longissimus dorsi) foram coletadas para avaliação da cinética do $\mathrm{P}$ nos tecidos.

A detecção da radioatividade nas amostras de plasma e dos tecidos foi realizada em espectrômetro de cintilação líquida por efeito Cerenkov (International..., 1979). O conteúdo de fósforo inorgânico no plasma foi determinado por colorimetria, segundo Fiske e Subbarrow (1925), e, nos tecidos, pelo método vanadatomolibidato (Sarruge e Haag, 1974). As análises foram realizadas no Laboratório de Nutrição Animal do Centro de Energia Nuclear na Agricultura da Universidade de São Paulo.

Os cálculos do percentual das atividades específicas $\left({ }^{32} \mathrm{P} / \mathrm{P}\right.$ total) foram feitos de acordo com Lofgreen (1960).

Para todos os tecidos coletados, calcularam-se, além da concentração de $\mathrm{P}$ ( $\mathrm{mg} / \mathrm{g}$ matéria seca), a retenção do $\mathrm{P}$ radioativo, a atividade específica padronizada (AEP) e a atividade específica relativa (AER), como descrito a seguir:

$$
\text { Retenção de }{ }^{32} \mathrm{P} \quad=\frac{\text { cpm da amostra do tecido/g MS }}{\mathrm{cmp} \text { dose injetada }}
$$

em que; $\mathrm{cpm}=$ contagem por minuto.

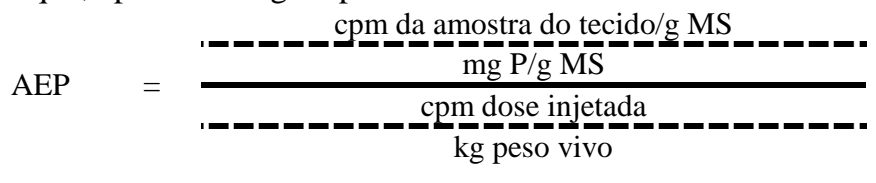

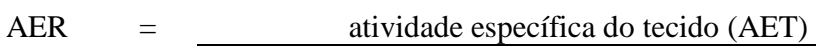
atividade específica do plasma (AEP) 
A meia-vida biológica e efetiva do fósforo foi determinada utilizando-se um sistema cartesiano com atividade específica no plasma, e o tempo de acordo com a lei de decaimento dos átomos radioativos (International..., 1979).

$\mathrm{T} 1 / 2=\frac{\ln 2}{\mathrm{~K}}$, em que: $\mathrm{K}=$ constante de decaimento biológico, calculado pela equação exponencial: $\mathrm{A}=$ Ao.e-kt, em que: $\mathrm{A}=$ atividade específica no instante $\mathrm{t}$; Ao $=$ atividade específica inicial $(\mathrm{t}=\mathrm{o}$ e $\mathrm{t}=$ tempo $)$.

A meia-vida biológica ( $\mathrm{Tb}$ ) mede a velocidade de desaparecimento do radioisótopo no plasma, e a meia-vida efetiva (Te) mede o desaparecimento nos tecidos; assim, a meia- vida biológica e a meia-vida efetiva constituem sinalizador do tempo de reciclagem dos minerais no plasma e nos tecidos. Neste contexto, quanto maior o valor observado, menor a velocidade de desaparecimento do mineral do plasma e dos tecidos. O desaparecimento do plasma constitui uma somatória das saídas via fezes, urina, tecidos e saliva, mas nos tecidos representa a velocidade de utilização para funções metabólicas e mobilização para o plasma.

A análise estatística dos parâmetros estudados no experimento foi realizada de acordo com o SAS (Statistical..., 2002). Utilizou-se o delineamento em esquema de parcela subdividida, sendo os níveis de fitase considerados como parcelas e os tecidos como subparcelas. Aplicou-se o "teste t" para comparar as médias entre os parâmetros estudados, e, para avaliar os efeitos da inclusão dos níveis crescentes de fitase nas dietas sobre a cinética nos tecidos, utilizou-se a análise de regressão por polinômios ortogonais.

\section{RESULTADOS E DISCUSSÃO}

O P consumido não foi afetado pela enzima fitase. Isto ocorreu porque, neste tipo de experimento, o consumo é padronizado, e os animais consumiram toda a dieta oferecida (Tab. 1).

As variáveis meia-vida biológica $(\mathrm{Tb})$, meia-vida efetiva (Te) e $\mathrm{P}$ plasma também não foram afetadas pela enzima fitase. Estes dados estão de acordo com os observados por Moreira (2002), que também não detectou efeito ao estudar estas variáveis.

A cinética nos tecidos foi avaliada pela retenção do ${ }^{32} \mathrm{P}$ e pelas atividades específicas padronizadas e relativas, tendo como base os valores médios das dietas suplementadas com fitase (Tab. 2). A maior concentração do ${ }^{32} \mathrm{P}$ foi observada nos rins, e a menor nos ossos. Estes dados estão em consonância com os observados por Lopes et al. (1999b) e Teixeira et al. (2004b), que também observaram menor retenção de ${ }^{32} \mathrm{P}$ no osso. Segundo Lopes et al. (1999b), esta baixa retenção do ${ }^{32} \mathrm{P}$ nos ossos pode estar associada ao curto período experimental (14 dias). Entretanto, na avaliação da atividade específica padronizada (AEP), que representa a padronização dos valores em relação ao peso dos animais, observaram-se maiores valores para os ossos, o que se justifica por ser este um tecido de grande mobilização de $\mathrm{P}$.

Tabela 1. Efeitos da enzima fitase na cinética do $\mathrm{P}$ nos tecidos de suínos em crescimento

\begin{tabular}{|c|c|c|c|c|c|}
\hline \multirow{2}{*}{ Variáveis } & \multicolumn{4}{|c|}{$\begin{array}{l}\text { Nível de inclusão de enzima fitase (UF/kg } \\
\text { de dieta) }\end{array}$} & \multirow[b]{2}{*}{ EPM } \\
\hline & $\begin{array}{c}0 \\
250\end{array}$ & 500 & 750 & 1000 & \\
\hline$P$ consumido (g/dia) & $\begin{array}{l}3,88 \\
4,11\end{array}$ & 3,81 & 3,94 & 3,81 & 0,1927 \\
\hline Meia-vida biológica (dias) & $\begin{array}{l}4,00 \\
3,89\end{array}$ & 4,21 & 4,41 & 3,83 & 0,0900 \\
\hline Meia-vida efetiva (dias) & $\begin{array}{l}3,11 \\
3,05\end{array}$ & 3,21 & 3,34 & 3,01 & 0,5242 \\
\hline P plasma (mg/100mL) & $\begin{array}{l}8,31 \\
8,10\end{array}$ & 8,66 & 8,54 & 8,83 & 0,5087 \\
\hline
\end{tabular}


Cinética do P...

Tabela 2. Cinética do $\mathrm{P}$ nos tecidos de suínos em crescimento

\begin{tabular}{lcccccc}
\hline \multirow{2}{*}{ Variáveis } & \multicolumn{7}{c}{ Tecidos } \\
\cline { 2 - 7 } & Coração & Fígado & Músculos & Osso & Rins & EPM \\
\hline${ }^{32}$ P retido $^{*}$ & $0,0073 \mathrm{a}$ & $0,0069 \mathrm{~b}$ & $0,0070 \mathrm{~b}$ & $0,0051 \mathrm{bb}$ & $0,0080 \mathrm{a}$ & 0,0189 \\
AEP $^{*}$ & $0,0500 \mathrm{~b}$ & $0,0585 \mathrm{~b}$ & $0,0500 \mathrm{~b}$ & $0,0790 \mathrm{a}$ & $0,0463 \mathrm{~b}$ & 0,0990 \\
A E R* $^{*}$ & $0,4889 \mathrm{~b}$ & $0,4632 \mathrm{~b}$ & $0,4808 \mathrm{~b}$ & $0,3429 \mathrm{~b}$ & $0,5609 \mathrm{a}$ & 0,0018 \\
\hline
\end{tabular}

*Médias seguidas de letras distintas na mesma linha diferem entre $\mathrm{si}(\mathrm{p}<0,05)$ pelo teste $\mathrm{t}$.

Os rins apresentaram maiores valores da atividade específica relativa (AER), o que indica ser este o órgão de maior mobilização do $\mathrm{P}$, tendência também observada por Lopes et al. (1999b) e Moreira et al. (2004).
Os parâmetros relacionados à cinética do $\mathrm{P}$ nos tecidos foram avaliados para detectar os efeitos dos níveis crescentes de enzima fitase sobre os tecidos do osso, músculo, coração, rins e fígado (Tab. 3).

Tabela 3. Efeito dos diferentes níveis de inclusão da enzima fitase nas dietas sobre a atividade específica padronizada (AEP) e a atividade específica relativa (AER) nos tecidos de suínos

\begin{tabular}{|c|c|c|c|c|c|c|c|}
\hline \multirow{2}{*}{ Tecidos } & \multirow{2}{*}{ Variáveis } & \multicolumn{5}{|c|}{ Níveis de enzima fitase nas dietas (UF/kg de dieta) } & \multirow{2}{*}{$\mathrm{CV} \%$} \\
\hline & & 0 & 250 & 500 & 750 & 1000 & \\
\hline \multirow{3}{*}{ Osso } & $\mathrm{AEP}^{*}$ & 0,120 & 0,082 & 0,074 & 0,061 & 0,062 & \multirow{3}{*}{21,73} \\
\hline & AER & 0,380 & 0,320 & 0,380 & 0,280 & 0,340 & \\
\hline & AEP & 0,007 & 0,006 & 0,007 & 0,006 & 0,008 & \\
\hline \multirow[t]{2}{*}{ Músculo } & AER & 0,070 & 0,051 & 0,048 & 0,041 & 0,038 & \multirow[t]{2}{*}{28,43} \\
\hline & $\mathrm{AEP}^{*}$ & 0,070 & 0,048 & 0,049 & 0,043 & 0,040 & \\
\hline \multirow[t]{2}{*}{ Coração } & AER & 0,460 & 0,420 & 0,580 & 0,480 & 0,500 & \multirow[t]{2}{*}{14,78} \\
\hline & $\mathrm{AEP}^{*}$ & 0,062 & 0,047 & 0,046 & 0,040 & 0,037 & \\
\hline \multirow[t]{2}{*}{ Rins } & $\mathrm{AER}^{* * *}$ & 0,500 & 0,530 & 0,710 & 0,540 & 0,520 & \multirow[t]{2}{*}{14,21} \\
\hline & $\mathrm{AEP}^{*}$ & 0,079 & 0,060 & 0,057 & 0,051 & 0,045 & \\
\hline Fígado & AER & 0,430 & 0,460 & 0,530 & 0,460 & 0,440 & 13,39 \\
\hline
\end{tabular}

*Efeito exponencial $(\mathrm{p}<0,05)$

**Efeito quadrático $(\mathrm{p}<0,05)$.

Ao se avaliarem os efeitos dos níveis crescentes de fitase nas dietas sobre a AEP nos tecidos, observou-se um efeito linear negativo para os tecidos do osso $(p<0,05)$ (Fig. 1) e para os tecidos do coração, rins e fígado. Estes dados são inversamente proporcionais aos observados por Moreira et al. (2011) no estudo da biodisponibilidade do $\mathrm{P}$ para suínos em crescimento. De acordo com Georgievskii (1982), a incorporação do fósforo nos vários tecidos e órgãos é variável e dependente da taxa de renovação e da fase de crescimento do animal. A troca desse mineral nos tecidos decresce com a idade e aumenta durante os períodos de atividade reprodutiva, sendo essas trocas mais intensas no fósforo lábil do esqueleto e na matéria esponjosa do osso.

O aumento do grau de desaparecimento do $\mathrm{P}$ nos tecidos com elevação dos níveis de fitase nas dietas indica que o $\mathrm{P}$ originário das moléculas de fitato pode ter sido utilizado preferencialmente pelos tecidos dos animais, pois, conforme constatado por diversos autores, a fitase atua no intestino disponibilizando $\mathrm{o} P$ fítico para $\mathrm{a}$ absorção; com isso, observa-se redução do $\mathrm{P}$ nas excreções (Moreira et al., 2011). Neste contexto, pode-se afirmar que a enzima fitase, além de atuar sobre a absorção e a excreção do $P$, também interfere na utilização do mineral pelos tecidos.

A ausência de efeitos da AEP nos tecidos do músculo pode ser atribuída ao uso intenso do $\mathrm{P}$ no metabolismo dos animais, o que levou ao maior grau de desaparecimento (Tab. 3).

A atividade específica relativa não afetou as variáveis: osso, coração, músculos e fígado, entretanto observou-se efeito quadrático positivo dos níveis de enzima fitase sobre a atividade relativa nos rins (Fig. 2). 


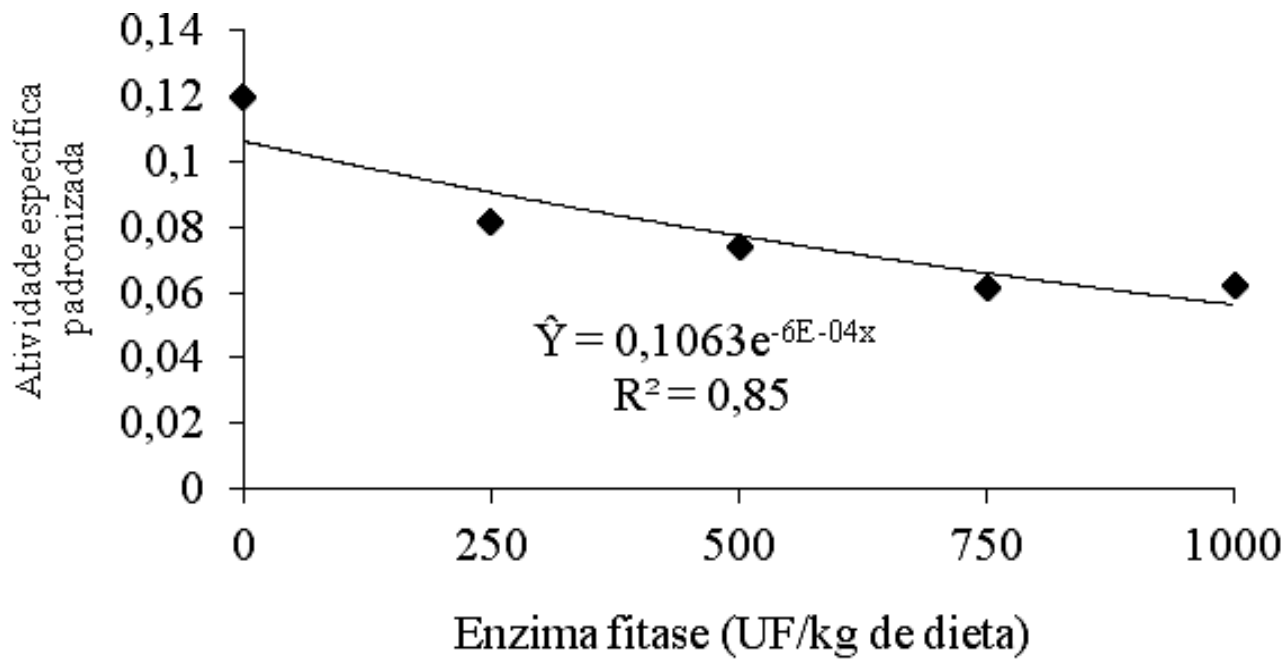

Figura 1. Efeito da enzima fitase sobre a atividade específica padronizada no osso.

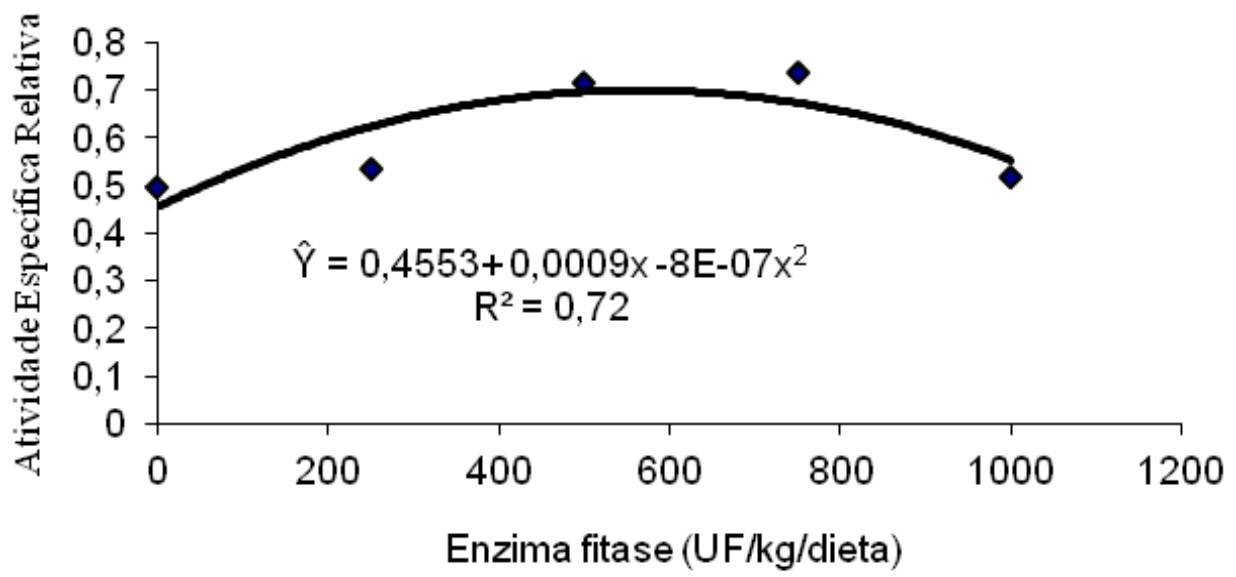

Figura 2. Efeitos da enzima fitase sobre atividade específica relativa nos rins.

A maior velocidade de incorporação do $\mathrm{P}$ nos tecidos ratifica os argumentos de que os tecidos dos suínos usam preferencialmente o $\mathrm{P}$ originário das moléculas de fitato, pois, embora se tenha detectado um fluxo crescente até o nível 750 (ponto máximo de resposta), a AEP nos tecidos apresentou-se inversamente proporcional, o que caracteriza o maior grau de utilização do $\mathrm{P}$ originário da molécula de fitato pelos tecidos.

\section{CONCLUSÃO}

O uso de enzima fitase nas dietas traz benefícios à suinocultura, pois, além de melhorar a absorção, reduzir a excreção, também interfere de forma benéfica na utilização do $\mathrm{P}$ pelos tecidos dos suínos. O grau de utilização do $\mathrm{P}$ das dietas foi inversamente proporcional ao intercâmbio do $\mathrm{P}$ do plasma para os tecidos dos rins até $750 \mathrm{UF} / \mathrm{kg}$ de dieta.

\section{AGRADECIMENTOS}

À Fundação de Amparo à Pesquisa do Estado de São Paulo, pelo apoio concedido a este projeto (Fapesp, no 06/57574-5 e 04/14532-5); à Abvista Feed Ingredients, pela doação da enzima fitase. 


\section{REFERÊNCIAS}

AGUDELO, J.H.; LINDERNANN, M.D.; CROMWEL, G.L. Phosphorus utilization in growing pigs fed a phosphorus dieficient diet supplement a rice bran product amended phytase. Rev. Colomb. Cienc. Pecuária, v.23, p.429-443, 2010

AROUCA, C.L.C.; FONTES, D.O.; SILVA et al. Exigência de fósforo disponível para suínos machos castrados selecionados para deposição de carne magra, dos 30 aos $60 \mathrm{~kg}$. Arq. Bras. Med. Zootec, v.61, p.1094-1103, 2009.

BENNETT, E.M; CARPENTER S. R.; CARACO, N.F. Human Impact on Erodable Phosphorus and Eutrophication: A Global Perspective. BioScience, v.52, p. 227-234, 2001.

BUENO, S.M. Níveis de fósforo para caprinos: metabolismo, cinética e digestibilidade aparente. 1997. 57f. Tese (Doutorado em Ciência Animal)

- Centro de Energia Nuclear na Agricultura Universidade de São Paulo, Piracicaba, SP.

FISKE, C.H.; SUBARROW, Y. The colorimetric determination of phosphorus. J. Biol. Chemistry, v.66, p.375-400, 1925.

GEORGIEVSKII, V.I. 1982. The physiological role of macroelements. In: GEORGIVIESKII, V.I., ANNENKOV, B.N., SAMOKHIN V.T. (Eds.) Mineral nutrition of animals.1. ed. London: Butterworths. P.91-170.

INTERNATIONAL ATOMIC ENERGY AGENCY IAEA. Laboratory training manual on the use of nuclear techniques in animal research. Vienna: IAEA, 1979. 299p. (Technical Report Series, 193).

LOFGREEN, G.P. The availability of the phosphorus in dicalcium phosphate, bone meal, soft phosphate and calcium phytate for madure wether. J. Nutr., v.70, p.58-62, 1960.

LOPES, J. B. Avaliação da absorção real e das perdas endógenas de fósforo para suínos pela técnica de diluição isotópica. 1998. 87f. Tese (Doutorado em Ciências) - Centro de Energia Nuclear na Agricultura, Universidade de São Paulo, Piracicaba. 1998.

LOPES, J.B.; KEBREAB, E.; VITTI, D.M.S.S. et al. Model on biological flow of phosphorus in growing pigs. Arq. Bras. Med. Zootec., v.61, p.691-697, 2009a.
LOPES, J.B.; VITTI, D.M.S.S.; FIGUEIRÊDO, A.V. et al. Cinética do fósforo em tecidos de suínos em crescimento. Rev. Bras. Zootec., v.28, p.779-784, 1999b.

LUDKE, M.C.M.M.; LOPEZ, J.; LUDKE, J.V. Fitase em dietas para suínos em crescimento: (i) impacto ambiental. Cienc. Rural, v.32, p.97-102, 2002.

MACHINSKY, T.G.; KESSLER, A. M.; RIBEIRO, A.M.L et al. Digestibilidade de nutrientes e balanço de $\mathrm{Ca}$ e $\mathrm{P}$ em suínos recebendo dietas com ácido butírico, fitase e diferentes níveis de cálcio. Cienc. Rural, v.40, p.2350-2355, 2010.

MEINERZ, C.C.; JUNIOR, A.F.G.; ASSI, L. et al. Geração de Resíduos Provenientes da Suinocultura na Região Oeste do Paraná: Um caso de insustentabilidade. I - Congresso Latino Americano de Suinocultura e Sustentabilidade Ambiental, 2011. <Disponível em http://inbradess.org.br/?page_id=175>, acessado em: 17/02/2012.

MOREIRA, J.A. Radiofósforo nos estudos de biodisponibilidade e perdas endógenas, cinética nos tecidos e modelo biomatemático, associado ao desempenho de suínos alimentados com dietas contendo fitase. 2002. 142f. Tese (Doutorado em Ciências) - Centro de Energia Nuclear na Agricultura, Universidade de São Paulo, Piracicaba, SP.

MOREIRA, J.A.; VITTI, D.M.S.S.; TRINDADE NETO, M.A. et al. Phytase enzyme in diets containing defatted rice brand for growing swine. Sci. Agric., v.60, p.631-636, 2003.

MOREIRA, J.A.; BERENCHTEIN, B.; VITTI, D.M.S.S. et al. Biodisponibilidade do $\mathrm{P}$ e digestibilidade aparente do $\mathrm{N}$ em dietas de suínos suplementadas com níveis crescentes de enzima fitase, balanceada de acordo com o conceito de proteína ideal. Arq. Bras. Med. Zootec., v.63, p.1511-1518, 2011.

MOREIRA, J.A.; VITTI, D.M.S.S.; LOPES, J.B.; TRINDADE NETO, M.A. Fluxo biológico do fósforo no metabolismo de suínos alimentados com dietas contendo fitase. Rev. Bras. Zootec., v.33, p.2066-2075, 2004.

ROSTAGNO, H.S.; ALBINO, L.F.T.; DONZELE, J.L. et al. Tabelas brasileiras para aves e suínos: composição de alimentos e exigências nutricionais. 3.ed. Viçosa: UFV, 2011. 252p. 
SARRUGE, J.R.; HAAG, H.P. Análises químicas em plantas. Piracicaba: ESALQ/USP, 1974. 56p.

STATISTICAL analysis system. The SAS system for windows. Release 8.01. Cary: SAS Institute, 2002.

TEIXEIRA, A.O.; LOPES, D.C.; LOPES, J.B. et al. Determinação da biodisponibilidade do fósforo de diferentes fontes pela técnica de diluição isotópica, em suínos em crescimento. Rev. Bras. Zootec, v.33, p.1231-1237, 2004a.

TEIXEIRA, A.O.; LOPES, D.C.; LOPES, J.B; VITTI, D.M.S.S. et al. Cinética do radiofósforo em tecidos de suínos alimentados com diferentes fontes de fósforo. Rev. Bras. Zootec., v.33, p.1238-1245, 2004b.
VITTI, D.M.S.S.; KEBREAB, E. Phosphorus and calcium utilization and requeriments in farm animals, 1.ed., Londres: Cabi Internation, 2010. 178p.

VITTI, D.M.S.S.; ROQUE, A.P.; DIAS, R.S. et al. Metabolismo de cálcio em ovinos em crescimento sob suplementação com diferentes fontes de cálcio: aplicação e comparação de dois modelos matemáticos. Rev. Bras. Zootec., v.35, p.2487-2495, 2006. 